\title{
Equitable access to HCV care in HIV-HCV co-infection can be achieved despite barriers to health care provision
}

This article was published in the following Dove Press journal:

Therapeutics and Clinical Risk Management

19 April 2010

Number of times this article has been viewed

\section{Curtis L Cooper' \\ Celine Giordano' \\ Dave Mackie' \\ Edward J Mills ${ }^{2}$}

'The University of Ottawa Division of Infectious Diseases Viral Hepatitis Program, Ottawa, Canada; ${ }^{2}$ Faculty of Health Sciences, Simon Fraser University, Burnaby, Canada
Correspondence: Curtis Cooper Associate Professor of MedicineUniversity of Ottawa, The Ottawa Hospital, Room GI2- 50 I Smyth Rd, Ottawa, ON, Canada, KIH 8L6

$\mathrm{Tel}+\mathrm{I} 6137378924$

Fax +l 6137378164

Email ccooper@ottawahospital.on.ca
Abstract: Language barrier, race, immigration status, mental health illness, substance abuse and socioeconomic status are often not considered when evaluating hepatitis C virus (HCV) sustained virological response (SVR) in human immunodeficiency virus (HIV) infection. The influence of these factors on HCV work-up, treatment initiation and SVR were assessed in an HIV-HCV coinfected population and compared to patients with HCV mono-infection. The setting was a publicly funded, urban-based, multidisciplinary viral hepatitis clinic. A clinical database was utilized to identify HIV and HCV consults between June 2000 and June 2007. Measures of access to HCV care (ie, liver biopsy and HCV antiviral initiation) and SVR as a function of the above variables were evaluated and compared between patients with HIV-HCV and HCV. HIV-HCV co-infected $(\mathrm{n}=106)$ and HCV mono-infected $(\mathrm{n}=802)$ patients were evaluated. HIV-HCV patients were more often white ( $94 \%$ versus $84 \%$ ) and male ( $87 \%$ versus $69 \%$ ). Bridging fibrosis or cirrhosis on biopsy was more frequent in HIV-HCV (37\% versus $22 \%$; $P=0.03)$. HIV infection itself did not influence access to biopsy ( $50 \%$ versus $52 \%$ ) or treatment initiation (39\% versus $38 \%$ ). Race, language barrier, immigration status, injection drug history and socioeconomic status did not influence access to biopsy or treatment. SVR was $54 \%$ in HCV and $30 \%$ in HIV-HCV $(P=0.003)$. Genotype and HIV were the only evaluated variables to predict SVR. Within the context of a socialized, multidisciplinary clinic, HIV-HCV co-infected patients received similar access to HCV work-up and care as HCV mono-infected patients. SVR is diminished in HIV-HCV co-infection independent of language barrier, race, immigration status, or socioeconomic status.

Keywords: HIV, HCV, sustained virological response, immigrant, language, barrier, race, health care access

\section{Introduction}

Human immunodeficiency virus (HIV) infection, hepatitis $\mathrm{C}$ virus (HCV) genotype, HCV RNA level, fibrosis stage and age are well established predictors of sustained virological response (SVR) with interferon and ribavirin-based HCV antiviral therapy. ${ }^{1-4}$ Language barrier, race, immigration status, mental health illness, history of substance abuse, and socioeconomic status are often not considered when evaluating SVR or other measures of HCV treatment availability, including access to HCV work-up and treatment initiation. This omission may be important, as racial and ethnic disparities concerning access to health care are well recognized in many disease states including HIV and HCV. ${ }^{5-7}$ This is relevant given the multilingual and multiracial make-up of the HCV-infected population in developed regions of the world, ${ }^{8-10}$ and the heavy burden of mental health illness ${ }^{8,9}$ and substance abuse ${ }^{10-12}$ faced by those living with HCV. Socioeconomic status is an additional obstacle to health care delivery, even in countries with publicly funded health care systems. ${ }^{16-18}$ 
The Ottawa Hospital Division of Infectious Disease Viral Hepatitis Program provides care for a diverse population of HIV-HCV co-infected and HCV mono-infected individuals consisting of Canadian-born individuals of multiple races, and immigrants from throughout the world. Expertise in viral hepatitis, HIV, nursing, and mental health are available as part of the basic services offered by the program. Assistance with linking to social work and substance abuse programs is provided. Services are available in English and French as well as in other languages through use of a translator. In this context of a publicly funded, diversely populated, urban-located, tertiary care hospital-based multidisciplinary viral hepatitis program, HCV work-up, treatment initiation and SVR were evaluated in a population of HIV-HCV co-infected patients and compared to those with HCV mono-infection. Identifying and understanding barriers to successful treatment outcomes in HIV-HCV co-infection is vital to ensure that optimal care is provided to all patients.

\section{Methods}

We used a clinical database for this analysis. Patients evaluated in clinic from June 2000 to June 2007, 18 years of age or older at the time of enrolment, and chronically infected with $\mathrm{HCV}$ (defined as HCV RNA positive more than six months after initial exposure) were included. Patient data extracted included HIV status, age, sex, race (White, Black, Asian, Aboriginal), primary language, immigration status (defined as a foreign-born resident of Canada), history of mental health illness, history of injection drug use, HBV status, HCV genotype, HCV RNA level, alanine aminotransferase (ALT) and aspartate aminotransferase (AST) levels. Hepatitis B surface antigen-positive patients were excluded from this analysis. If a patient had received more than one course of HCV antiviral therapy, only the most recent was considered. All formulations of interferon and ribavirin HCV antiviral therapy were included. SVR rate was defined as HCV RNA negative six months after completion of HCV antiviral therapy. A language barrier was defined as non-English and non-French speaking.

The 2006 Canadian Census dataset was used to obtain information on patient socioeconomic status. Each patient was assigned to a census dissemination area using their residential postal code. Using this reference point, average measures of socioeconomic variables, as represented in the census tract denominations, were attributed to each patient. The census dissemination-level socioeconomic variables included in the analyses were percent of residents with post-secondary education, percent of residents who were unemployed, percent of residents living below the Canadian poverty line, and median before tax neighborhood income.

Outcome measures focused on pre-HCV antiviral therapy management, proportion initiating interferon-ribavirin, supportive care while on HCV treatment, and SVR. Access to pre-HCV-treatment was evaluated by the proportion receiving a liver biopsy, because this is considered a standard of care procedure for HCV treatment evaluation. This was controlled for by genotype in order to account for the potential influence of this parameter on biopsy frequency.

Statistical analyses were conducted with SPSS version 16.0 (SPSS Inc., Chicago, IL). Chi square and $t$-test analyses were used to assess whether a measure of access differed by HIV status. Predictors of liver biopsy, treatment initiation and SVR were assessed by multivariable logistic regression analysis. Genotype, age, fibrosis stage, HCV RNA level, and HIV status as well as sex, race, immigration status, language category, history of mental health illness and history of injection drug use were assessed. We applied a backward step regression approach. We considered a $P$-value of $<0.05$ as significant. The Ottawa Hospital Research Ethics Board approved this study and patient consent was obtained for use of all data.

\section{Results}

Between June 2000 and June 2007, 908 patients with chronic HCV infection were evaluated, of which 106 $(12 \%)$ were HIV-HCV co-infected (Table 1). HIV-HCV co-infected patients were more likely to be younger, male, Canadian-born, White, and infected with genotypes 1, 2, or 3 when compared to HCV mono-infected patients. The burden of past injection drug use and mental health illness was similar. A language barrier was identified in $4 \%$ of $\mathrm{HCV}$ mono-infected and in none of the HIV-HCV co-infected patients. Based on 2006 Canadian Census data, HIV-HCV co-infected patient's financial status was similar to $\mathrm{HCV}$ mono-infected individuals (Table 1).

Liver biopsy rates were similar between HIV-HCV co-infected and HCV mono-infected patients (50\% [n $=53]$ versus $52 \%[\mathrm{n}=415] ; P=0.74)$. Fewer patients with genotype 2 or 3 infection underwent liver biopsy compared to other genotypes that typically received longer duration therapy (96/233 [41\%] versus 372/675 [55\%]; $P<0.001)$. This was true irrespective of HIV positive (11/28 [39\%]) or negative $85 / 205[41 \%])$ status $(P=0.83)$. Despite a younger mean age, the proportion of HIV-HCV co-infected patients with advanced fibrosis (Stage 3 or 4 by Scherer System) was greater than in HCV mono-infection (37\% versus $22 \%$; $P=0.03$ ). 
Table I Baseline patient characteristics

\begin{tabular}{|c|c|c|c|}
\hline $\begin{array}{l}\text { Continuous variables } \\
\text { mean (standard deviations) }\end{array}$ & HIV-HCV & HCV & $P$ value \\
\hline N (\% of Total) & $106(12 \%)$ & $802(88 \%)$ & \\
\hline Age (years) & $42(7)$ & $45(10)$ & 0.003 \\
\hline Weight (Kg) & $74(15)$ & $79(18)$ & 0.03 \\
\hline Mean HCV RNA (IU/mL) & $1.33 \times 10^{6}\left(1.41 \times 10^{6}\right)$ & $1.72 \times 10^{6}\left(7.00 \times 10^{6}\right)$ & 0.59 \\
\hline ALT (IU/L) & $78(53)$ & $82(69)$ & 0.54 \\
\hline AST (IU/L) & $73(54)$ & $64(57)$ & 0.16 \\
\hline HIV RNA (copies/mL) & $31,001(78,602)$ & - & - \\
\hline CD4 count (cells/ $\mu \mathrm{L})$ & $450(272)$ & - & - \\
\hline Categorical variables & $N=106$ & $N=802$ & \\
\hline Male sex & $87 \%$ & $69 \%$ & $<0.001$ \\
\hline On HAART at first visit & $58 \%$ & - & - \\
\hline HIV RNA below lower limit of detection & $49 \%$ & - & - \\
\hline Immigrant & $9 \%$ & $22 \%$ & 0.003 \\
\hline History of mental health illness & $47 \%$ & $49 \%$ & 0.72 \\
\hline History of injection drug use & $58 \%$ & $57 \%$ & 0.46 \\
\hline Bridging fibrosis or cirrhosis on biopsy & $37 \%$ & $22 \%$ & 0.03 \\
\hline HCV RNA $>600,000$ copies $/ \mathrm{mL}$ & $67 \%$ & $55 \%$ & 0.03 \\
\hline \multicolumn{4}{|l|}{ Genotype } \\
\hline I & $70 \%$ & $68 \%$ & 0.64 \\
\hline 2 & $4 \%$ & $8 \%$ & 0.07 \\
\hline 3 & $22 \%$ & $17 \%$ & 0.13 \\
\hline 4 & $4 \%$ & $5 \%$ & 0.55 \\
\hline 5 & 0 & $1 \%$ & - \\
\hline 6 & 0 & $1 \%$ & - \\
\hline Self-reported race & & & 0.03 (overall) \\
\hline White & $94 \%$ & $84 \%$ & 0.02 \\
\hline Black & $6 \%$ & $8 \%$ & 0.68 \\
\hline Asian & 0 & $5 \%$ & - \\
\hline Aboriginal & 0 & $3 \%$ & - \\
\hline Spoken language & & & 0.20 (overall) \\
\hline English & $74 \%$ & $78 \%$ & 0.27 \\
\hline French & $26 \%$ & $18 \%$ & 0.03 \\
\hline Chinese/Vietnamese & 0 & $2 \%$ & - \\
\hline Arabic & 0 & $1 \%$ & - \\
\hline Other & 0 & $<1 \%$ & - \\
\hline \multicolumn{4}{|l|}{ Socioeconomic } \\
\hline Yearly median neighborhood income (Canadian dollars) & $\$ 26,157$ & $\$ 27,937$ & 0.11 \\
\hline Low income strata' & $20 \%$ & $19 \%$ & 0.52 \\
\hline Urban setting & $83 \%$ & $86 \%$ & 0.52 \\
\hline High school education & $77 \%$ & $78 \%$ & 0.29 \\
\hline Bachelors degree or Higher & $22 \%$ & $25 \%$ & 0.16 \\
\hline Unemployment & $7.5 \%$ & $7.6 \%$ & 0.88 \\
\hline
\end{tabular}

Notes: 'Defined as bottom quintile. 
By univariate logistic regression, individuals with genotype 1 (odds ratio [OR] 1.79 [1.35, 2.37]; $P<0.001$ ), mental health illness (OR 1.34 [1.03, 1.74]; $P=0.03$ ), and history of injection drug use (OR 1.33 [1.03, 1.74]; $P=0.03]$ were more likely to undergo liver biopsy. Only genotype remained significant by multivariate analysis (OR 1.73 [1.31, 2.31]; $P<0.001]$.

The proportion of HIV-HCV co-infected patients initiating treatment $(39 \%[\mathrm{n}=41])$ was similar to $\mathrm{HCV}$ mono-infected patients $(38 \%[\mathrm{n}=304])(P=0.88)$. Genotype 2 and 3 infected patients were not more likely to initiate therapy than those with genotype 1, 4, 5 or 6 infection if HIV seropositive (11/28 [39\%] versus 30/78 [38\%]; $P=0.94]$. This was in contrast to HIV seronegative patients (94/205 [46\%] versus 210/596 [35\%]; $P=0.07)]$. HCV mono-infected females were less likely to initiate therapy than males (79/246 [32\%] versus 225/556 [40\%]; $P=0.03)$ but not when HIV-HCV co-infected (6/14 [43\%] versus 35/92 [38\%]; $P=0.73$ ). Advanced fibrosis (OR 2.35 [1.48, 3.73]; $P<0.001$ ), male sex (OR 1.38 [1.02, 1.87]; $P=0.04)$ and older age (OR 1.02 [1.00, 1.03]; $P=0.02)$ predicted treatment initiation (univariate regression analysis). Advanced fibrosis remained significant (OR $2.50[1.56,4.03]$; $P<0.001)$ as a predictor of treatment initiation when these variables were controlled for. Socioeconomic factors did not influence the likelihood of treatment initiation (data not shown).

Overall, SVR was achieved in $51 \%$ of patients (162/316) initiating $\mathrm{HCV}$ therapy with available final treatment outcome data. SVR rates differed by HIV status (12/40 [30\%] versus 150/275 [55\%]; $P=0.004$ ) (Figure 1). This was consistent for specific genotypes. Genotype 1 status (OR 2.73 [1.60, 4.63]; $P<0.001)$ and HIV infection (OR 2.70 [1.26, 5.81]; $P=0.01$ ) were key predictors of reduced SVR. Immigration status, language category, mental health illness, history of substance use and socioeconomic status did not influence SVR in this cohort of treatment recipients (data not shown).

Although limited by sample size, the influence of combination antiretroviral therapy (cART) on outcome measures was evaluated in HIV-HCV co-infected patients. Thirty-four of 41 (83\%) HIV seropositive patients were on cART at the time that HCV antiviral treatment was initiated. The mean CD4 count was 549 (274) cells/ $\mu \mathrm{L}$ in those on therapy and $524(161)$ cells $/ \mu \mathrm{L}$ in those not receiving antiretroviral therapy $(P=0.81)$. Liver biopsy rates were similar between those receiving cART (22 of 34 [65\%]) and those not (4 of $7[57 \%])(P=0.71)$. Erythropoietin use was required in 10 of $34(29 \%)$ cART recipients and 0 of $7(0 \%)$ patients receiving no HIV treatment $(P=0.11)$. Erythropoietin use was greater in zidovudine recipients: 4 of 7 (57\%) versus 6 of $27(22 \%)(P=0.07)$. SVR was achieved in 10 of $33(30 \%)$ and 2 of $7(29 \%)$ individuals, respectively $(P=0.93)$. Abacavir was used in 2 of $10(20 \%)$ cART-treated patients achieving a SVR and 8 of $23(35 \%)$ who did not $(P=0.40)$.

\section{Discussion}

$\mathrm{HIV}$ and HCV frequently co-exist. As a consequence, liver disease is a primary cause of morbidity and mortality in HIV. ${ }^{13} \mathrm{HIV}$ co-infection accelerates progression to cirrhosis, liver failure and liver-specific death. ${ }^{14,15}$ Although sustained virological response (SVR) is diminished in $\mathrm{HIV}-\mathrm{HCV}$ co-infection, ${ }^{1,4}$ successful clearance of chronic HCV infection with antiviral therapy reduces liver fibrosis and inflammation which presumably prevents cirrhosis, liver failure and liver-specific death. The risk of antiretroviral-related hepatotoxicity may also be reduced.

In spite of these potential benefits the majority of $\mathrm{HIV}-\mathrm{HCV}$ co-infected patients do not initiate HCV antiviral therapy as a consequence of multiple concurrent barriers to care. ${ }^{16-18} \mathrm{HIV}$ infection itself has been identified as a potential barrier to the provision of health care. ${ }^{19}$ Even if not overt, unrecognized biases may influence access to work-up and care in this population. Our analysis suggests that within a specialized and multidisciplinary publicly-funded clinic there are well-recognized barriers to HCV work-up and treatment initiation that can be overcome to maximize the level of care provided to those living with $\mathrm{HCV}$. In our evaluation, this was true irrespective of HIV status. Multidisciplinary models for the treatment of HIV have been proven to be effective. ${ }^{20}$ A publicly funded, multidisciplinary clinical care model for $\mathrm{HIV}-\mathrm{HCV}$ co-infected patients including integrated support from addiction medicine, mental health, and social work may also provide positive outcomes.

Our analysis suggests that patients with a history of mental health illness or substance abuse concerns are more likely to undergo liver biopsy. We suspect that this reflects a bias by clinicians to favor pursuit of therapy only in those with advanced stages of liver fibrosis, given the negative effect of interferon on these conditions. Our analysis of treatment initiation importantly suggests that mental health illness does not negatively influence starting therapy. Furthermore, we demonstrated that despite concurrent HIV infection and other barriers to care, liver fibrosis stage was the single most important variable influencing whether a patient initiates therapy.

Immigration status, race, language barriers and socioeconomic factors impede access to $\mathrm{HCV}$-related health care in developed regions of the world..$^{6,721-24}$ Our analyses 


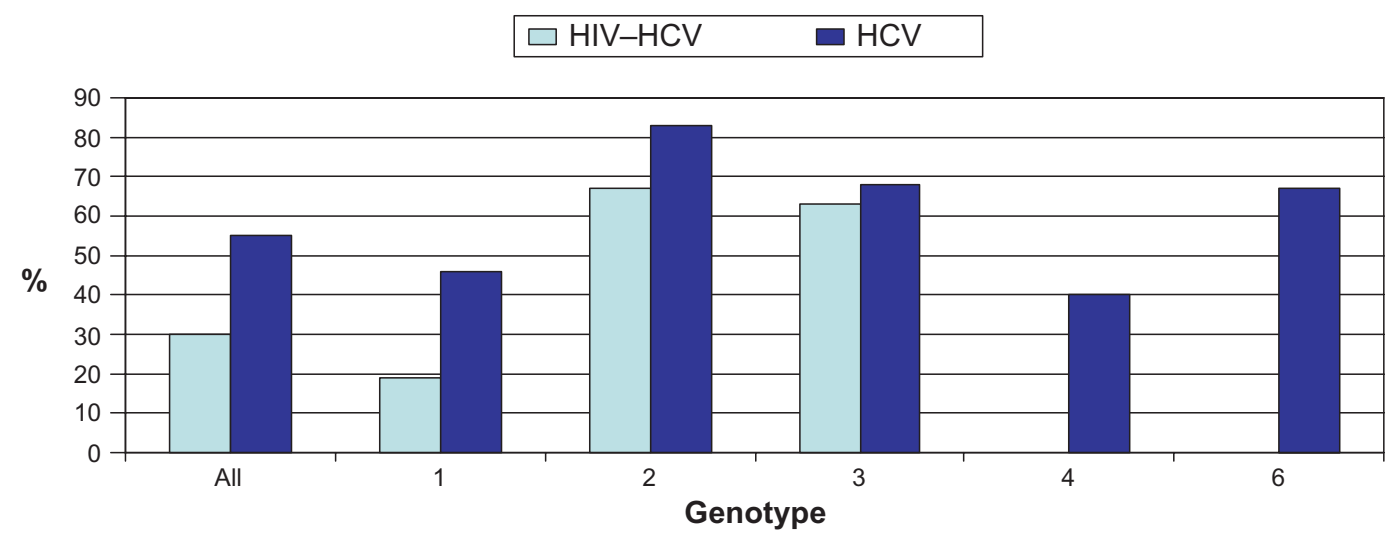

\begin{tabular}{|c|c|c|c|}
\hline Genotype & HIV-HCV & HCV & $P$ value \\
\hline All & $30 \%(12 / 40)$ & $55 \%(150 / 275)$ & 0.004 \\
\hline 1 & $19 \%(5 / 26)$ & $46 \%(79 / 173)$ & $<0.01$ \\
\hline 2 & $67 \%(2 / 3)$ & $83 \%(25 / 30)$ & 0.48 \\
\hline 3 & $63 \%(5 / 8)$ & $68 \%(40 / 59)$ & 0.77 \\
\hline 4 & $0 \%(0 / 3)$ & $40 \%(4 / 10)$ & 0.19 \\
\hline 5 & - & - & - \\
\hline 6 & - & $67 \%(2 / 3)$ & - \\
\hline
\end{tabular}

Figure I Sustained virological response by HIV status and genotype.

Abbreviations: $\mathrm{HCV}$, hepatitis $\mathrm{C}$ virus; HIV, human immunodeficiency virus.

suggest that these issues do not inevitably lead to substandard HCV care, irrespective of HIV status. Several factors may have facilitated the equity of care achieved in our setting. The Canadian health care system is publicly funded and universal in access. The likelihood of visiting a physician is primarily related to health care needs and chronic conditions but less influenced by socioeconomic status and education level. ${ }^{25,26}$ Although access to care disparities should not exist within this system, lower socioeconomic and educational levels have nonetheless been associated with a reduced likelihood of referral to specialist care..$^{25,27,28}$ There is a long history of managing diverse populations within our urban, hospital-based clinics. Our staff is aware of these obstacles and as a consequence makes a concerted effort to provide equal care to all patients. As well, the institutional emphasis on equal access to health care services in both French and English likely increases health care provider awareness of language barriers, thereby reducing the potential negative impact of this obstacle to care.

Consistent with our previous findings and other reports, HIV co-infection is a key predictor of reduced SVR with HCV treatment. ${ }^{1,4,29}$ Our analysis suggests that concomitant barriers to successful treatment outcome, which include poverty, language barriers and mental health disease, did not further diminish overall SVR and specifically in $\mathrm{HIV}-\mathrm{HCV}$ co-infection. In other words, the reduced SVR in those with HIV-HCV co-infection appears to be entirely biological in nature and not due to concurrent barriers to therapeutic success. Although limited by sample size, our findings suggest that the concurrent use of cART or specific antiretrovirals does not influence the likelihood of achieving a SVR.

There are strengths and limitations to consider when interpreting our analysis. Strengths include dataset integrity. The dataset used for this retrospective database evaluation had minimal missing data and was carefully assessed for inaccuracies prior to conducting the statistical analysis. Limitations of our study include its retrospective design, single site evaluation, and a lack of generalizability to nonpublicly-funded sites. However, our clinic population of HIV-HCV co-infected and HCV mono-infected patients are similar in characteristics to other North American, European, and Australian populations. ${ }^{30}$ Therefore, we believe that these results are broadly applicable. A high proportion of our patients were White which also influences generalizability.

Our study found that equitable access to HCV care in HIV-HCV co-infection can be achieved in spite of the presence of well-established barriers to health care provision and outcomes. The influence of these obstacles may be eliminated by recognizing their potential to diminish the quality of and access to care and establishing a health care infrastructure 
that can provide the complex care required by this population. Health care provision by a publicly funded, multidisciplinary team appears to facilitate the delivery of equitable care to those living with $\mathrm{HCV}$, irrespective of HIV co-infection.

\section{Acknowledgments}

CC acknowledges the Ontario HIV Treatment Network for Career Scientist support. CG's work was supported, in part, by a 2007 Canadian Liver Foundation Summer Studentship Award. The authors report no conflicts of interest in this work.

\section{References}

1. Carrat F, Bani-Sadr F, Pol S, et al. Pegylated interferon alfa-2b vs standard interferon alfa-2b, plus ribavirin, for chronic hepatitis $\mathrm{C}$ in HIVinfected patients: a randomized controlled trial. JAMA. 2004;292(23): 2839-2348.

2. Fried MW, Shiffman ML, Reddy KR, et al. Peginterferon alfa-2a plus ribavirin for chronic hepatitis $\mathrm{C}$ virus infection. $N$ Engl J Med. 2002;347(13):975-82.

3. Manns MP, McHutchison JG, Gordon SC, et al. Peginterferon alfa$2 \mathrm{~b}$ plus ribavirin compared with interferon alfa- $2 \mathrm{~b}$ plus ribavirin for initial treatment of chronic hepatitis C: a randomised trial. Lancet. 2001;358(9286):958-965.

4. Torriani FJ, Rodriguez-Torres M, Rockstroh JK, et al. Peginterferon alfa-2a plus ribavirin for chronic hepatitis $\mathrm{C}$ virus infection in HIVinfected patients. $N$ Engl J Med. 2004;351(5):438-450.

5. Nabalamba A, Millar WJ. Going to the doctor. Health Rep. 2007; 18(1):23-35

6. Trooskin SB, Navarro VJ, Winn RJ, et al. Hepatitis C risk assessment, testing and referral for treatment in urban primary care: role of race and ethnicity. World J Gastroenterol. 2007;13(7):1074-1078.

7. Butt AA, Justice AC, Skanderson M, Rigsby MO, Good CB, Kwoh CK. Rate and predictors of treatment prescription for hepatitis C. Gut. 2007;56(3):385-389.

8. Balfour L, Cooper C, Kowal J, et al. Depression and cigarette smoking independently relate to reduced health-related quality of life among Canadians living with hepatitis C. Can J Gastroenterol. 2006;20(2):81-86.

9. Dwight MM, Kowdley KV, Russo JE, Ciechanowski PS, Larson AM, Katon WJ. Depression, fatigue, and functional disability in patients with chronic hepatitis C. J Psychosom Res. 2000;49(5):311-317.

10. Cooper CL, Mills EJ. Therapeutic challenges in hepatitis C-infected injection drug using patients. Harm Reduct J. 2006;3:31.

11. Remis RS. Epidemiology of hepatitis $C$ virus infection in Canada. The 2nd Canadian Conference of Hepatitis C. Vancouver, BC: Canadian Viral Hepatitis Network, 2004.

12. Stein MD, Charuvastra A, Anderson BJ. Social support and zero sharing risk among hazardously drinking injection drug users. J Subst Abuse Treat. 2002;23(3):225-230.

13. Rosenthal E, Pialoux G, Bernard N, et al. Liver-related mortality in human-immunodeficiency-virus-infected patients between 1995 and 2003 in the French GERMIVIC Joint Study Group Network (MORTAVIC 2003 Study). J Viral Hepat. 2007;14(3):183-188.
14. Benhamou Y, Bochet M, Di Martino V, et al. Liver fibrosis progression in human immunodeficiency virus and hepatitis $\mathrm{C}$ virus coinfected patients. The Multivirc Group. Hepatology. 1999;30(4):1054-1058.

15. Lesens O, Deschenes M, Steben M, Belanger G, Tsoukas CM. Hepatitis $\mathrm{C}$ virus is related to progressive liver disease in human immunodeficiency virus-positive hemophiliacs and should be treated as an opportunistic infection. J Infect Dis. 1999;179(5):1254-1258.

16. Fleming CA, Craven DE, Thornton D, Tumilty S, Nunes D. Hepatitis $\mathrm{C}$ virus and human immunodeficiency virus coinfection in an urban population: low eligibility for interferon treatment. Clin Infect Dis. 2003;36(1):97-100.

17. Restrepo A, Johnson TC, Widjaja D, et al. The rate of treatment of chronic hepatitis $\mathrm{C}$ in patients co-infected with HIV in an urban medical centre. J Viral Hepat. 2005;12(1):86-90.

18. Thompson VV, Ragland KE, Hall CS, Morgan M, Bangsberg DR. Provider assessment of eligibility for hepatitis $\mathrm{C}$ treatment in HIV-infected homeless and marginally housed persons. AIDS. 2005;19(Suppl 3): S208-S214.

19. Mahajan AP, Sayles JN, Patel VA, et al. Stigma in the HIV/AIDS epidemic: a review of the literature and recommendations for the way forward. AIDS. 2008;22(Suppl 2):S67-S79.

20. Mitty JA, Stone VE, Sands M, Macalino G, Flanigan T. Directly observed therapy for the treatment of people with human immunodeficiency virus infection: a work in progress. Clin Infect Dis. 2002;34(7):984-990.

21. Green AR, Ngo-Metzger Q, Legedza AT, Massagli MP, Phillips RS, Iezzoni LI. Interpreter services, language concordance, and health care quality. Experiences of Asian Americans with limited English proficiency. J Gen Intern Med. 2005;20(11):1050-1056.

22. Jacobs E, Chen AH, Karliner LS, Agger-Gupta N, Mutha S. The need for more research on language barriers in health care: a proposed research agenda. Milbank Q. 2006;84(1):111-133.

23. Jacobs EA, Lauderdale DS, Meltzer D, Shorey JM, Levinson W, Thisted RA. Impact of interpreter services on delivery of health care to limitedEnglish-proficient patients. J Gen Intern Med. 2001;16(7):468-474.

24. Weech-Maldonado R, Morales LS, Elliott M, Spritzer K, Marshall G, Hays RD. Race/ethnicity, language, and patients' assessments of care in Medicaid managed care. Health Serv Res. 2003;38(3):789-808.

25. Dunlop S, Coyte PC, McIsaac W. Socio-economic status and the utilisation of physicians' services: results from the Canadian National Population Health Survey. Soc Sci Med. 2000;51(1):123-133.

26. Finkelstein MM. Do factors other than need determine utilization of physicians' services in Ontario? CMAJ. 2001;165(5):565-570.

27. Haider A, Mamdani M, Shaw JC, Alter DA, Shear NH. Socioeconomic status influences care of patients with acne in Ontario, Canada. J Am Acad Dermatol. 2006;54(2):331-335.

28. Steele LS, Glazier RH, Lin E. Inequity in mental health care under Canadian universal health coverage. Psychiatr Serv. 2006;57(3):317-324.

29. Giordano $\mathrm{C}$, Cooper $\mathrm{C}$. The influence of race and language on chronic hepatitis C virus infection management. Eur J Gastroenterol Hepatol. 2009;21(2):131-136

30. Centers for Disease Control and Prevention. HIV/AIDS C: Fact Sheets-CDC HIV/AIDS. Atlanta, GA: Department of Health and Human Services, 2009
Therapeutics and Clinical Risk Management

\section{Publish your work in this journal}

Therapeutics and Clinical Risk Management is an international, peerreviewed journal of clinical therapeutics and risk management, focusing on concise rapid reporting of clinical studies in all therapeutic areas, outcomes, safety, and programs for the effective, safe, and sustained use of medicines. This journal is indexed on PubMed Central, CAS,
Dovepress

EMBase, Scopus and the Elsevier Bibliographic databases. The manuscript management system is completely online and includes a very quick and fair peer-review system, which is all easy to use. Visit http://www.dovepress.com/testimonials.php to read real quotes from published authors. 